\title{
Pathogenic activity of circulating anti-desmoglein-3 autoantibodies isolated from pemphigus vulgaris patients
}

Joanna Narbutt ${ }^{1}$, Joanna Boncela², Katarzyna Smolarczyk², Cezary Kowalewski ${ }^{3}$ Katarzyna Wozniak ${ }^{3}$, Jolanta Dorota Torzecka ${ }^{1}$, Anna Sysa-Jedrzejowska1', Czesław S. Cierniewski², Aleksandra Lesiak ${ }^{1}$

1Department of Dermatology, Medical University of Lodz, Poland ${ }^{2}$ Centre of Medical Biology, Polish Academy of Sciences, Lodz, Poland ${ }^{3}$ Department of Dermatology, Medical University of Warsaw, Poland

Submitted: 7 July 2010

Accepted: 18 August 2010

Arch Med Sci 2012; 8, 2: 347-356

DOI: 10.5114/aoms.2012.28564

Copyright (c) 2012 Termedia \& Banach

\section{Abstract}

Introduction: There are scarce data on immunochemical properties of pemphigus antibodies detected in clinical remission in pemphigus vulgaris (PV) patients. The aim of the study was to compare biological activity of anti-Dsg3 autoantibodies purified from the sera of PV patients in active stage and in clinical remission.

Material and methods: The effect of purified antibodies on expression of procaspase- 3 , Bax, Bcl-2, UPAR, IL- $1 \beta$, IL- 6 , and TNF- $\alpha$ mRNAs in the HaCaT keratinocytes was evaluated by Western blot and RT-PCR method.

Results: Incubation of HaCaT cells with anti-Dsg-3 autoantibodies caused their binding to cell membranes surfaces. Anti-Dsg3 autoantibodies isolated from the patients in active stage and clinical remission showed proapoptotic effect, caused enhanced expression of analyzed proinflammatory cytokines' mRNAs and UPAR mRNA.

Conclusions: Our data revealed similar pathogenic activity of anti Dsg-3 autoantibodies isolated from active and clinical remission PV patients.

Key words: pemphigus vulgaris, anti-Dsg-3 antibodies, acantholysis, keratinocyte culture, apoptosis.

\section{Introduction}

Pemphigus is an autoimmune blistering disease, affecting skin and mucous membranes. It is a life-threatening disease which demands longlasting immunosuppressive treatment. Pemphigus is divided into two distinct subtypes: pemphigus vulgaris (PV) and pemphigus foliaceus (PF). The antigens in pemphigus are desmogleins (Dsg), transmembrane desmosomal glycoproteins belonging to the cadherins supergene family of calciumdependent adhesion molecules. The Dsg $1(160 \mathrm{kDa})$ is the autoantigen recognized by PF antibodies, whereas Dsg3 (130 kDa) is recognized by PV antibodies. However, in about $50-70 \%$ of PV patients' sera anti-Dsg1 autoantibodies are present as well [1]. Anti-Dsg autoantibodies interfere with the adhesive function of desmogleins and cause loss of cell-cell adhesion. Recent studies suggest that IgG pemphigus autoantibodies may uniquely react with, apart from desmogleins, approximately 20 proteins (molecular masses range from $12 \mathrm{kDa}$ to $219 \mathrm{kDa}$ ) which also may play an important role in acantholysis development $[2,3]$. Despite extensive research, the

\author{
Corresponding author: \\ Joanna Narbutt MD, PhD \\ Department of Dermatology \\ and Venerology \\ Medical University of Lodz \\ 5 Krzemieniecka \\ 94-017 Lodz, Poland \\ Phone: +48 426867981 \\ Fax: +48 426884565 \\ E-mail: \\ joanna.narbutt@umed.lodz.pl
}


exact aetiopathogenesis of pemphigus is still unclear and no objective criteria of complete cure of the disease have been established so far. The direct immunofluorescence test (DIF) detecting bound in vivo IgG deposits in the intercellular spaces of the epidermis and the indirect immunofluorescence test (IIF) showing circulating IgG antibodies are routine examinations in diagnosing pemphigus, and their negative findings may indicate stopping treatment.

In some cases, however, despite long lasting treatment and lack of clinical symptoms, both immunological examinations are still positive. It seems controversial, especially because most dermatologists assume a strong correlation between the titre of pemphigus antibodies and the disease activity. There are scarce data on immunochemical properties of antibodies detected in clinical remission and their potential ability to initiate acantholysis. In this process various pathways including proinflammatory cytokine mRNA expression and apoptosis are involved. Apoptosis is a physiological process essential for the maintenance of homeostasis by elimination of damaged or mutated cells. Multiple pathways and a variety of environmental, extracellular and internal signals are responsible for the activation and regulation of this process [4]. Classical apoptosis requires activation of caspases. Caspase-dependent apoptosis is activated through either receptor (external) or mitochondrial (internal) pathways. One of the main regulators of apoptosis is the family of $\mathrm{Bcl}-2$ proteins, consisting of both apoptosis inhibitors, such as Bcl-2 and Mcl-1, and pro-apoptotic proteins, such as Bax, Bak and Bad. The ratio of Bax : $\mathrm{BCl}-2$ determines the death or life of the cells [5]. Both initiator caspase pathways activate effector caspases subsequently, mainly caspase- 3 , and caspases- 6 and caspases-7 to a lesser extent [6]. In addition, one of the signals leading to apoptosis is DNA damage, inducing cell death by the pathway orchestrated by members of the p53 (p53, p73) and Bcl-2 families [7]. Although there are many data on the role of apoptosis in multiple skin diseases, its role in pemphigus development is still not clear.

In keratinocyte cultures stimulated with PV-lgG, in the presence of IFN- $\gamma$, enhanced expression of FasR, FasL, caspases and DNA degradation were observed after 10-30 h, while acantholysis was noted only after 2-3 days. Immunohistochemical analysis showed increased expression and altered distribution of proteins belonging to DISC and FADD families, as well as enhanced expression of caspase- 8 and caspase- 3 . These phenomena led to intra-epidermal blister formation. These results suggest that apoptosis is followed by acantholysis [8].

In another study, Frusic-Zlotkin et al. [9] revealed that keratinocyte and organ cultures upon incubation with PV-lgG had increased activity of caspase-3 and caspase- 8 and these authors used caspase activity to monitor biological properties of pemphigus antibodies in regard to their binding to epithelia. Wang et al. [10] revealed that PV-lgG antibodies induced Fas-dependent apoptotic events and their activity depends on culture age. They showed that aged human keratinocyte cultures are more sensitive to PV-IgG mediated apoptotic phenomena than younger ones, which may partially provide some explanation for late onset of PV. It was also suggested that dysregulation of apoptotic pathways and no proper clearance of apoptotic material in PV patients my act as antigens and in consequence lead to autoantibody synthesis [11]. Most studies on apoptosis in pemphigus have been performed with the use of IgG antibodies isolated from active patients. There are no published papers concerning apoptotic activities of purified anti-Dsg3 antibodies isolated either from active PV patients or from patients in clinical remission.

Although the pathogenic role of pemphigus autoantibodies is widely proven, more and more studies indicate the possibility of their occurrence in $30-70 \%$ of healthy relatives of pemphigus patients $[12,13]$. In these cases we can detect by IIF antibodies of a pattern typical for pemphigus (fishnet-like) in the intercellular spaces of epithelium (monkey and/or guinea-pig oesophagus). This pattern is identical to a true 'pemphigus' one, and in most cases distinguishing between them is impossible. In the individuals in whom circulating antibodies are detected, DIF is usually negative, indicating the lack of reactions of these antibodies with target pemphigus antigens in the epidermis. In our studies performed in healthy relatives of pemphigus patients we detected circulating autoantibodies in $40 \%$ of cases by IIF [14]. According to our knowledge, there are no studies on the immunochemical properties and potential pathogenic role of IgG antibodies taken from this sero-positive group of healthy relatives of $\mathrm{PV}$ patients.

The aim of our study was to evaluate biological activity of anti-Dsg3 antibodies, immunochemically purified from patients with the active stage of $\mathrm{PV}$ and patients on maintenance treatment (clinical remission). Additionally we checked whether IgG antibodies isolated from healthy relatives of PV patients in whom IIF showed circulating pemphigus antibodies in low titres have similar properties. The effect of examined antibodies on expression of procaspase-3, Bax, $\mathrm{Bcl}-2$, urokinase plasminogen activator receptor (UPAR), IL-1 $\beta$, IL-6, and TNF- $\alpha$ mRNAs in the HaCaT keratinocytes was evaluated.

\section{Material and methods}

\section{Patients}

To isolate autoantibodies we used sera obtained from: (1) patients in an active stage of disease 
$(n=18 ; 6 \mathrm{M}$ and $12 \mathrm{~F}),(2)$ in clinical remission ( $n=14 ; 7 \mathrm{M}$ and $7 \mathrm{~F})$, (3) healthy relatives $(n=5$; $1 \mathrm{M}$ and $4 \mathrm{~F}$ ) of patients with pemphigus and (4) control donors $(n=7)$. Pemphigus was diagnosed based on clinical picture, histological examination (acantholysis and intra-epidermal blister formation), DIF (bound in vivo IgG deposits in intercellular spaces of spinous layer of epidermis) and IIF (circulating pemphigus antibodies). Clinical remission was considered when patients presented with no mucocutaneous skin lesions at least for 6 months and were on maintenance therapy (mean prednisone dose $40 \mathrm{mg}$ every second day and mean cyclophosphamide dose $50 \mathrm{mg}$ every second day). The healthy relatives group consisted of the relatives of PV patients who selectively showed circulating pemphigus antibodies in IIF with no simultaneous presence of any skin or mucous lesions. The control donors group consisted of sera obtained from healthy unrelated subjects, age and sex matched. The study protocol was approved by the Ethics Committee of the Lodz Medical University. All subjects gave written informed consent before entering the study.

All sera were examined by IIF using commercially available substrates: guinea pig and monkey oesophagus (Euroimmune, Lubeka, Germany) by a standard procedure [15]. Mean titres of pemphigus autoantibodies obtained from patients in the active stage of the disease, in the remission phase and those of healthy relatives were $1 / 1280,1 / 320$, $1 / 160$, respectively. The same sera samples were examined by ELISA (MESACUP DESMOGLEIN TEST Dsg-1 and Dsg-3; MBL Co. Ltd, Nagoya, Japan) according to the manufacturer's instructions. ELISA index was assessed as positive when it was higher than the cut-off for Dsg-1 and Dsg-3 equalled 14 and 7, respectively. Mean indices of anti-Dsg-3 antibodies obtained from patients in the active stage of the disease and in the remission phase were 144 $\mathrm{IU} / \mathrm{ml}$ and $96 \mathrm{IU} / \mathrm{ml}$, respectively. In sera of the healthy relatives the ELISA test gave negative results. All sera were heated at $56^{\circ} \mathrm{C}$ for $30 \mathrm{~min}$ to inactivate complement, aliquoted and stored at $-80^{\circ} \mathrm{C}$.

\section{Methods \\ Expression of recombinant Dsg-3 in Escherichia coli and purification}

To express the recombinant protein fragment corresponding to the entire extracellular domain of Dsg-3 (1715 bp), two cDNA fragments (1281 bp and 434 bp) were PCR amplified using cDNA obtained from $\mathrm{HaCaT}$ cells with the following primers: 5'ggcaaggatccgaatgggtgaaatttg 3' and 5' ggcaattttagaattcaagtggtttgg 3'; 5'ccaaaccacttgaattctaaaattgcc 3' and 5' gcaggctcgagcctccctgagtg 3'. The
$1281 \mathrm{bp}$ PCR product was digested with $\mathrm{Bam} \mathrm{HI}$ and Ecol restriction enzymes and cloned into PRSET A plasmid (Invitrogen). The obtained plasmid was then used for cloning the second 434 bp PCR product using EcoRI and Xhol restriction sites. The full insert was sequenced and proved to be in the correct frame. Thus, the rDsg-3 fragment was expressed with high efficiency in E. coli BL 21(DE3) strain as a His-tag fusion protein containing 12 additional residues (MRGSHHHHHHGS) at its N-termini. The recombinant Dsg-3 fragment was next isolated from inclusion bodies dissolved in $6 \mathrm{M}$ urea by chromatography on a Chelating Sepharose Fast Flow column (Amersham Biosciences), loaded with $\mathrm{Ni}$ ions according to the manufacturer's instructions. Purification and refolding of recombinant Dsg-3 was performed as described in $[16,17]$.

\section{Isolation of patient autoantibodies}

Autoantibodies were purified from sera of patients by affinity chromatography using the immobilized recombinant fragment of Dsg-3 corresponding to its entire extracellular fragment. For this purpose, rDsg-3 was bound to Chelating Sepharose Fast Flow resin (Amersham Biosciences) loaded with $\mathrm{Ni}$ ions. Briefly, sera samples were incubated with the resin at $4^{\circ} \mathrm{C}$ overnight with gentle rocking and then antibodies bound to the rDsg-3$\mathrm{His}$ resin were eluted with the IgG elution buffer (100 mM glycine, pH 3.0), immediately neutralized with $0.5 \mathrm{M}$ Tris- $\mathrm{HCl}$, pH 8.0, dialysed against phosphate-buffered saline (PBS, $\mathrm{pH} 7.4$ ) and concentrated with a Microsep 30 microconcentrator. As anti-Dsg-3 antibodies were undetectable by ELISA in sera of healthy relatives, despite the presence of pemphigus antibodies found by IIF in this group of subjects, their entire lgG fraction was isolated. IgGs from healthy relatives were isolated using the standard technique with HiTrap Protein A HP columns according to the manufacturer's instructions (Amersham Biosciences). The IgG samples were fractionated by precipitation with $40 \%$ ammonium sulfate, dialysed against PBS, and concentrated using a Microsep 30 microconcentrator (Pall Life Science, Ann Arbor, MI, USA). The purity of isolated IgGs was monitored by western immunoblotting and its binding specificity tested by ELISA. Purified autoimmune IgGs were stored at the concentration of $10 \mathrm{mg}$ per $\mathrm{ml}$ in $\mathrm{PBS}$ at $-80^{\circ} \mathrm{C}$.

\section{Cell culture}

A spontaneously immortalized human keratinocyte cell line, HaCaT [18], was cultured in DMEM supplemented with $100 \mathrm{U} / \mathrm{ml}$ penicillin, $100 \mu \mathrm{g} / \mathrm{ml}$ streptomycin, and $10 \%$ FBS at $37^{\circ} \mathrm{C}$ in an atmosphere of $5 \% \mathrm{CO}_{2}$. For experiments, cells were subcultured in 6-well plates and maintained to $90 \%$ 
confluency. Then, the culture medium was discarded, and the cells were pre-incubated in DMEM supplemented with $0.1 \%$ BSA for $24 \mathrm{~h}$. For mRNA analysis, the medium was replaced with fresh serum-free medium containing autoimmune or control IgG $(1 \mathrm{mg} / \mathrm{ml})$. Cells were harvested after $24 \mathrm{~h}$ and total mRNA isolated.

\section{Assessment of mRNA levels}

Total RNA was extracted from the keratinocytes by the Micro-to-Midi Total RNA Purification system (Invitrogen, Carlsbad, CA, USA). The first strand of cDNA was synthesized according to the manufacturer's instructions (Promega Corp., Madison, WI, USA) using oligo dT primer. The reverse transcription was carried out for $60 \mathrm{~min}$ at $30^{\circ} \mathrm{C}$ and stopped at $4^{\circ} \mathrm{C}$. The primer sequences for amplification of TNF- $\alpha$, IL-6, IL-1 and u-PAR mRNAs were 5'gtagcccatgttgtagcaaacc 3' and 5'gaggacctgggagtagatgagg 3', 5'acctgaaccttccaaagatgg 3' and 5'gactgcaggaactccttaaagc 3', 5'ctcgccagtgaaatgatgg 3' and 5'gcatcttcctcagcttgtcc 3', and 5' ggtgaagaagggcgtccaaagg 3' and 5' ttctgcggcagattttcaagctc 3', respectively. RT-PCR assay conditions were as follows: $1 \mu \mathrm{l}$ of cDNA sample, 20× Tfl polymerase buffer, $2.5 \mathrm{mM}$ $\mathrm{MgCl}_{2}, 1 \times$ PCR enhancer, dNTP mix, 25 pmol of each primer and $1 \mathrm{U}$ of Tfl DNA polymerase (Epicentre Biotechnologies, Madison, WI, USA) in $25 \mu \mathrm{lreac}-$ tion volume. The samples were denatured at $95^{\circ} \mathrm{C}$ for $5 \mathrm{~min}$, then cooled on ice and the enzyme was added. The reaction was performed in 25 to 30 extension cycles consisting of a $30 \mathrm{~s}$ denaturation step at $94^{\circ} \mathrm{C}$, a $30 \mathrm{~s}$ annealing step at $55^{\circ} \mathrm{C}$, and a $30 \mathrm{~s}$ polymerase extension step at $72^{\circ} \mathrm{C}$. Finally, each reaction was terminated with a 10 min elongation step at $72^{\circ} \mathrm{C}$. To detect actin mRNA, the same protocol was used with the oligodeoxyribonucleotide primers 5'cagcagattcaagcagctatgg3' and 5'gtctgtggtgctgatctcatcc3'. The final products, TNF- $\alpha$, IL-6, IL-1 $\beta$ and actin mRNAs, were separated by electrophoresis in $1.5 \%$ agarose gels in TAE buffer using the genetic size marker 100 bp DNA Ladder (Promega). Bands were visualized by UV light, recorded photographically and analysed densitometrically

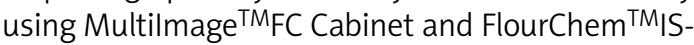
8800 Software v.3.0 (Alpha Innotech Corp., San Leonardo, CA, USA). Concentrations of mRNA in each sample were normalized in relation to $\beta$-actin $\mathrm{mRNA}$. Usually 4-6 bands were analysed for each sample and the mean value was calculated. The mean \pm SD was then calculated for each group.

\section{Western blot analysis}

$\mathrm{HaCaT}$ cells were incubated in serum-free medium (KSFM, GIBCO-Invitrogen) in the presence or absence of PV autoantibodies or normal human IgG for $8 \mathrm{~h}$. Cell lysates were prepared using RIPA buffer
(Pirece Co.) and protein concentrations were determined using the BCA method. One hundred $\mu \mathrm{g}$ of protein from each of the cell lysates was loaded into SDS/PAGE and then gels were transferred onto nitrocellulose membranes (BioRad). Next, membranes were incubated for $1 \mathrm{~h}$ at room temperature with polyclonal rabbit antibodies to human procaspase-3 (Santa Cruz), or monoclonal antibodies to human Bcl-2 (Santa Cruz), Bax (Santa Cruz) or actin (Santa Cruz), respectively. Bound antibodies were detected with corresponding second antibodies conjugated with horseradish peroxidase, namely mouse anti-rabbit immunoglobulin (Promega) or goat antimouse (Santa Cruz), respectively. All antibodies were used at a dilution according to the manufacturer's instructions. Bands were visualized by autoradiography with ECL Reagent (Pierce Co.)

\section{Confocal microscopy}

Cells were grown directly $\left(5 \times 10^{4}\right.$ cells $\left./ \mathrm{ml}\right)$ on tissue culture chamber slides (Nunc). After $24 \mathrm{~h}$ incubation in the presence of PV autoantibodies $(1 \mathrm{mg} / \mathrm{ml})$ or normal human $\mathrm{lgG}(1 \mathrm{mg} / \mathrm{ml})$, HaCaT cells were rinsed 3 times with cold PBS and dipped in $-20^{\circ} \mathrm{C}$ methanol for $20 \mathrm{~min}$. Next, cells were stained with Texas Red-X phalloidin according to the manufacturer's instructions (Molecular Probes) to visualize actin filaments and analysed with a fluorescence microscope (Nikon). In some experiments, cells grown $\left(5 \times 10^{4}\right.$ cells $\left./ \mathrm{ml}\right)$ on tissue culture chamber slides (Nunc) for $18 \mathrm{~h}$ were used to dye their nuclei with Hoechst 33342 (Molecular Probes). Then they were rinsed 3 times with cold PBS and fixed with 3\% paraformaldehyde for 20 min on ice and blocked with 10\% normal goat serum (Santa Cruz). Afterwards, cells were incubated with PV autoantibodies $(1 \mathrm{mg} / \mathrm{ml})$ or normal human IgG $(1 \mathrm{mg} / \mathrm{ml})$ for $1 \mathrm{~h}$ at room temperature and treated for $1 \mathrm{~h}$ with goat anti-human IgG-TRIC (Santa Cruz) used at the dilution of $1: 100$. Finally, slides were rinsed with PBS, and chambers were removed and mounted with glass slides in mounting media with 3\% DABCO (Sigma).

\section{Statistical analysis}

Statistical analysis was performed using Statistica v.5.0 and GraphPad Prism v.4.03. As laboratory data did not fit a Gaussian distribution according to the Shapiro-Wilk test, all results were expressed by the median ( $50^{\text {th }}$ percentile) and interquartile range $\left(25^{\text {th }}-75^{\text {th }}\right.$ percentile), and non-parametric tests were used to test statistical significance of differences in laboratory parameters. To avoid errors inherent in repeated application of Mann-Whitney $U$ tests, the Kruskal-Wallis test was performed to make simultaneous comparison of the assay data from each of the three groups of subjects, and to 
determine if there was significant variation in the medians of the groups analysed. If it achieved $95 \%$ significance, Dunn's multiple comparison post-test was used to compare the assay results of one group with another.

\section{Results}

\section{Isolation and characterization of anti-Dsg-3} autoantibodies

The recombinant fragment of Dsg-3 corresponding to its entire extracellular domain was expressed in E. coli as a His-tag fusion protein, purified on nickel chelating columns in $6 \mathrm{M}$ urea, and refolded by sequential dialysis to remove the denaturant. The final product was soluble in aqueous buffers and was homogeneous as assessed by SDSPAGE (Figure $1 \mathrm{~A}$ ). This protein was then used to isolate autoantibodies from blood sera of pemphigus vulgaris patients in an active stage of disease or in clinical remission. For this purpose, rDsg-3 was bound to Chelating Sepharose Fast Flow resin (Amersham Biosciences) loaded with $\mathrm{Ni}$ ions, after overnight incubation with samples of patient sera, antibodies bound to the rDsg-3-His resin were eluted with $0.1 \mathrm{M}$ glycine buffer, $\mathrm{pH} 3.0$, and immediately neutralized. Anti-Dsg-3 autoantibodies separated by SDS PAGE showed homogeneity (Figure $1 \mathrm{~B}$ ). When immobilized on microtitre plates, the recombinant rDsg-3 fragment reacted with both types of autoantibodies, namely those isolated from patients with the active state of PV or with disease remission, respectively (Figure $1 \mathrm{C}$ ). Incubation of $\mathrm{HaCaT}$ cells with anti-Dsg-3 autoantibodies resulted in their binding to cell membrane surfaces (Figure 2 A-B). Autoantibodies were mostly found in regions adjacent to the plasma membrane, but to some extent there was also diffuse staining in the whole cytoplasm. This staining was specific since IgGs obtained from healthy or control donors were negative in control cells additionally stained with Hoechst 33258 to visualize their nuclei (Figure 2 C-D).

\section{Anti-Dsg-3 autoantibodies from pemphigus vulgaris patients in active or remission phase differ in their anti-adhesive activity}

In the next experiments we compared the effect of autoantibodies on the actin filament network in keratinocytes after staining of cells with TRITC-phalloidin (Figure $3 \mathrm{~A}$ ). Incubation of $\mathrm{HaCaT}$ cells for $24 \mathrm{~h}$ with anti-Dsg-3 autoantibodies isolated from patients in the active stage of the disease resulted in reorganization of the actin cytoskeleton typical for apoptotic cells (Figure $3 \mathrm{~A}$, picture a). The microfilament system of such cells was focally enriched in regions located subjacent to the plasma membrane and nucleus. In contrast, cells treated with control IgG obtained from healthy relatives or con- trol donors showed a well-developed system of the actin filament network typical of adhering and spread cells. They also formed intercellular connections (Figure $3 \mathrm{~A}$, pictures $\mathrm{c}$ and $\mathrm{d}$ ). Interestingly, $\mathrm{HaCaT}$ cells incubated with anti-Dsg-3 autoantibodies isolated from patients in the remission phase were more similar to control cells with the actin filament network near normal and showing

A B

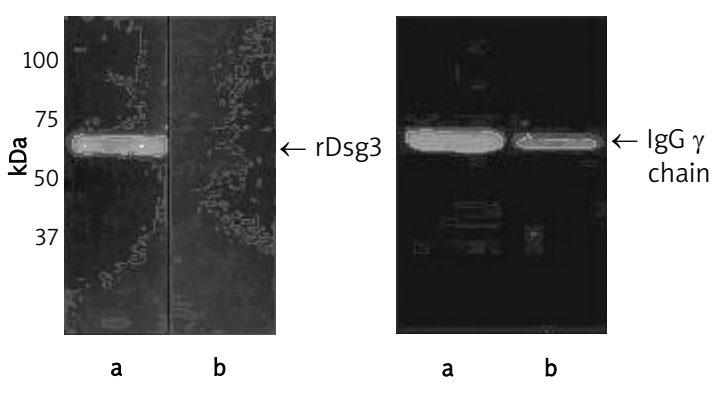

C

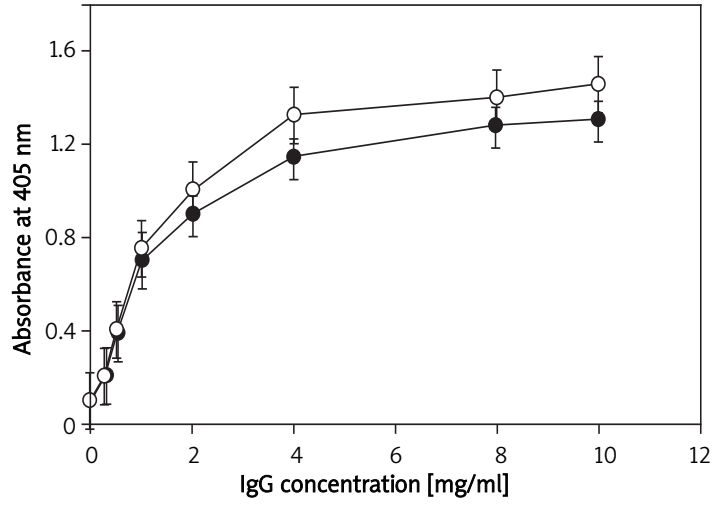

Figure 1. Characteristics of recombinant Dsg-3 and anti-Dsg-3 autoantibodies. Recombinant proteins expressed in E. coli and purified by affinity chromatography on Chelating Sepharose Fast Flow resin were separated by SDS-PAGE and immunoblotted with serum obtained from PV patients used at the dilution $1: 1000$ (panel A, lane a) and normal human serum used as a negative control (panel A, lane b). Recombinant Dsg-3 was used to isolate autoantibodies from PV patients' sera. Purified IgGs were separated by SDS-PAGE and immunoblotted with rabbit anti-human IgG conjugated with horseradish peroxidase and visualized by ECL. The affinity purified autoantibodies from PV patients in active state (panel B, lane a) or in remission stage (panel B, lane b) appeared to be homogeneous. Panel $C$ shows binding of anti-Dsg-3 antibodies purified from serum

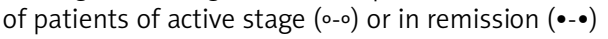
detected by solid phase binding assay. For this purpose, wells of 96-well plates were coated overnight at $4^{\circ} \mathrm{C}$ with rDsg-3 used at the concentration of 100 $\mu \mathrm{g} / \mathrm{ml}$ in PBS. Bound antibodies were detected with rabbit anti-human IgG conjugated with horseradish peroxidise. To detect non-specific binding, the wells were coated with BSA and the background binding to such wells was subtracted from all samples before data analysis 

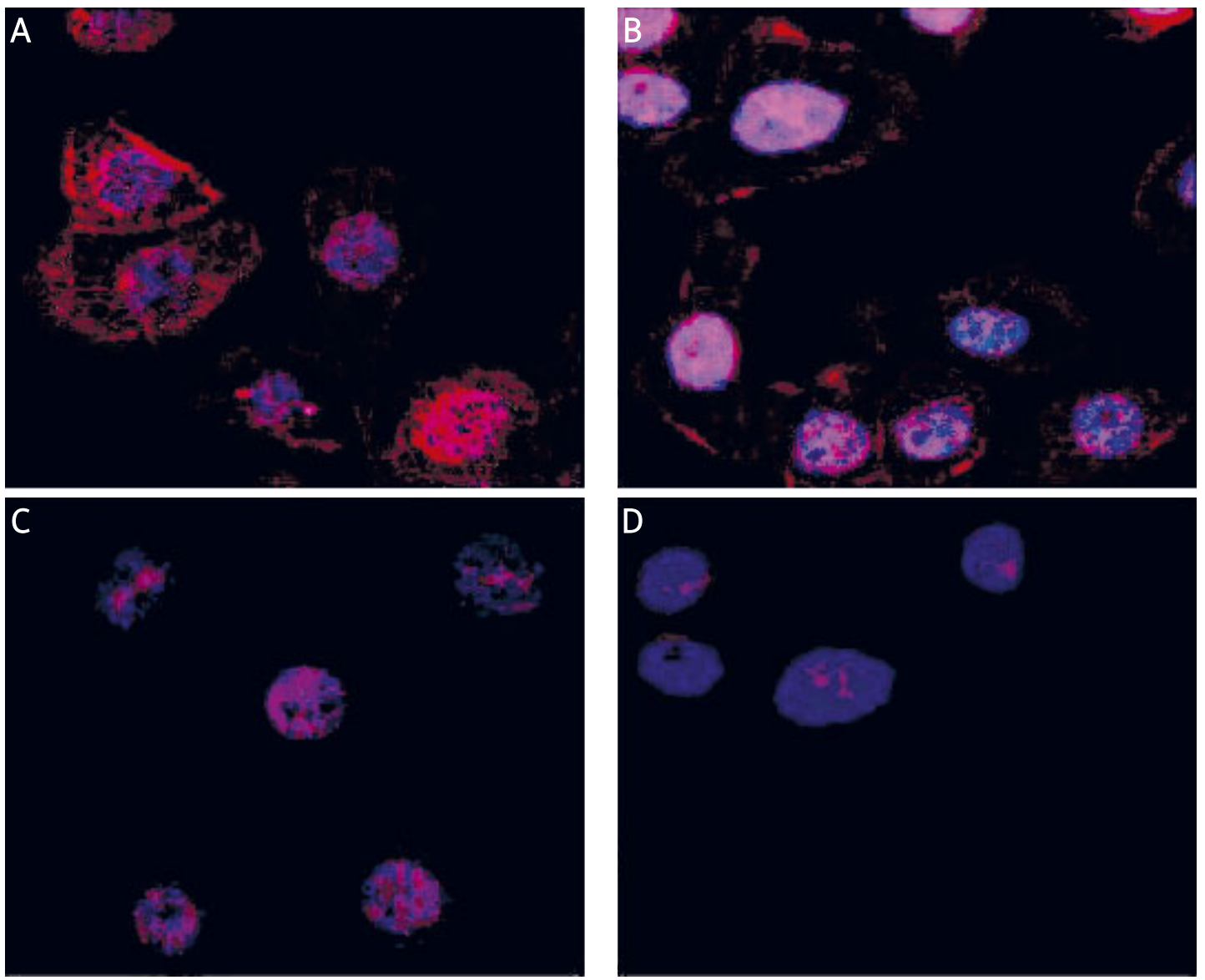

Figure 2. Binding of anti-Dsg-3 autoantibodies to $\mathrm{HaCaT}$ analysed by confocal microscopy. Cells grown directly on tissue culture chamber slides were incubated with anti-Dsg-3 autoantibodies isolated from PV patients in the active stage (A) or in remission (B) used at $1 \mathrm{mg} / \mathrm{ml}$. Control cells were incubated with $1 \mathrm{gGs}$ obtained from healthy relatives (C) of control donors (D) also used at $1 \mathrm{mg} / \mathrm{ml}$. Then they were rinsed with PBS, fixed with $3 \%$ paraformaldehyde for 20 min on ice, blocked with 10\% normal goat serum and after blocking with BSA stained with goat antihuman IgG conjugated with TRITC. Cell nuclei were visualized using Hoechst 33342

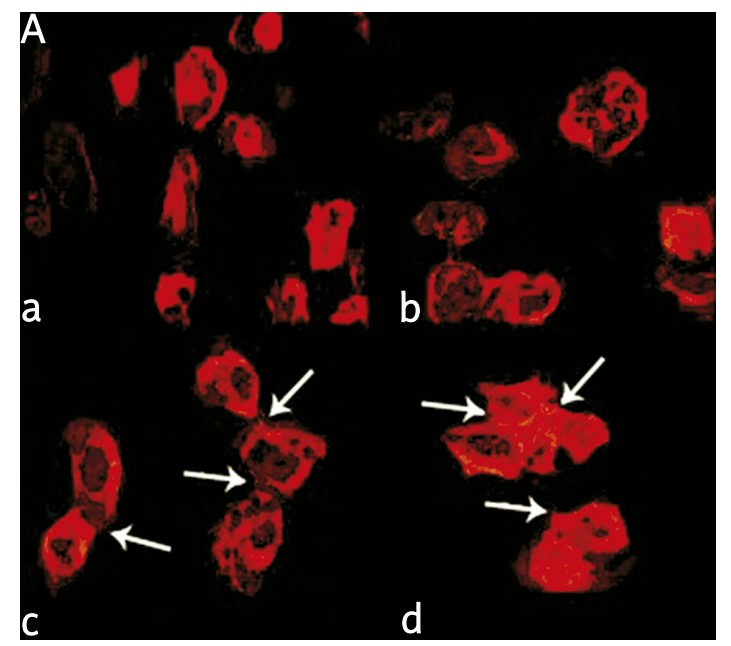

B

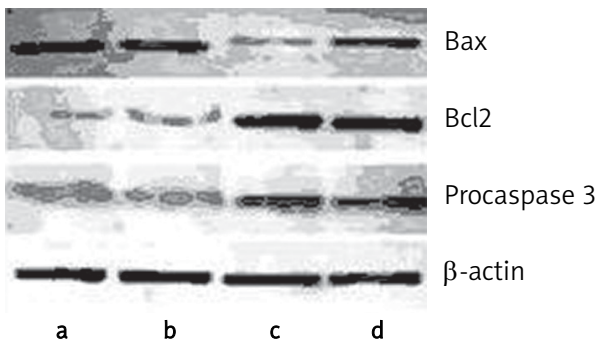

Figure 3. Reorganization of cytoskeleton induced by anti-Dsg-3 autoantibodies. HaCaT cells were incubated for $24 \mathrm{~h}$ with anti Dsg-3 autoantibodies isolated from patients in active (panel A, picture a) or remission stage (panel A, picture $\mathrm{b}$ ) used at the concentration of $1 \mathrm{mg} / \mathrm{ml}$. Control cells were incubated with $\mathrm{ggG}$ of healthy relatives (picture c) or control donors (picture d) used at the same concentration. Then, $\mathrm{HaCaT}$ cells were rinsed with cold PBS, dipped in $-20^{\circ} \mathrm{C}$ methanol for 20 min and stained with Texas Red-X phalloidin to visualize actin filaments. Panel $B$ shows Western blot analysis of Bax, Bcl proteins and procaspase 3 levels in HaCaT cells incubated in the presence of anti Dsg-3 autoantibodies isolated from PV patients at the active stage (lane a), patients in remission (lane b), healthy relatives (lane $c$ ) and healthy donors (lane d). $\beta$-Actin was used as a control for SDS/PAGE loading 
a tendency to form cell-to-cell contacts (Figure $3 \mathrm{~A}$, picture b). It is noteworthy that structural changes induced in keratinocytes by anti-Dsg-3 autoantibodies shown in Figures $3 \mathrm{~A}$ were observed in a number of cells (from 47 to 95 ) analysed by confocal microscopy during three separate experiments.

Consistently, Western blot analysis showed increased expression of Bax protein in human $\mathrm{HaCaT}$ cells incubated with both types of anti-Dsg-3 autoantibodies. At the same time, the expression of $\mathrm{Bcl}-2$ and procaspase-3 was significantly decreased in both groups, indicating that these antibodies had pro-apoptotic activity when incubated with keratinocytes (Figure $3 \mathrm{~B}$ ). No differences in $\mathrm{Bax}, \mathrm{Bcl}-2$ and procaspase- 3 expression were found between healthy relatives and healthy donors.

\section{Anti-Dsg-3 autoantibodies from pemphigus vulgaris patients induce expression of proinflammatory cytokines in keratinocytes}

Figure 4 shows that incubation of $\mathrm{HaCaT}$ cells with anti Dsg-3 autoantibodies resulted in a significant increase of proinflammatory cytokines such as IL-1 $\beta$, IL- 6 , and TNF- $\alpha$ when analysed at their mRNA level. Both types of autoantibodies showed a similar activating effect, though those obtained from patients in the active stage of the disease appeared to be more effective; however, these differences did not reach statistical significance. Statistical analysis of these data revealed that the only significant differences in mRNA expression for IL-1 $\beta$, IL-6, and TNF- $\alpha$ were between active PV stage patients and healthy relatives (controls) $(p<0.05$; $p<0.01 ; p<0.05$, respectively) (Table I, Figure 4).

The mRNA UPAR expression in HaCaT cells under incubation with anti-Dsg3 isolated from active PV patients was higher than in the controls, but this did not reach statistical significance. In contrast, the expression of mRNA for this protein in $\mathrm{HaCaT}$ cells stimulated by anti-Dsg-3 isolated from serum of patients in the remission stage of PV was significantly higher than in the cell lines stimulated by IgGs from healthy relatives of PV patients $(p<0.01$; Table I, Figure 4).

\section{Discussion}

The positive correlation between titres of pemphigus autoantibodies and pemphigus activity has been widely proven and the lack of antibodies in IIF was established as a criterion to stop treatment. However, in clinical practice we can observe by IIF

Table I. mRNA expression of interleukin-1 (IL-1), interleukin-6 (IL-6), tumour necrosis factor- $\alpha$ (TNF- $\alpha$ ) and receptor for urokinase-type plasminogen activator (UPAR) in $\mathrm{HaCaT}$ cell lines stimulated with anti-Dsg3 antibodies isolated from patients in the active (PV active) and remission (PV remission) stage of PV

\begin{tabular}{|lcc|}
\hline $\begin{array}{l}\text { Expression } \\
\text { of mRNA }\end{array}$ & $\begin{array}{c}\text { PV active } \\
\text { Median } \\
\text { (interquartile } \\
\text { range, } \\
25^{\text {th-75th }} \\
\text { percentile) }\end{array}$ & $\begin{array}{c}\text { PV remission } \\
\text { Median } \\
\text { (interquartile } \\
\text { range, } \\
25^{\text {th-75th }} \\
\text { percentile) }\end{array}$ \\
\hline IL-1 [\%] & 141 (133-148.5) & 129 (123.5-134.5) \\
\hline IL-6 [\%] & $197(188-205.5)$ & $174.5(169-183)$ \\
\hline TNF- $\alpha$ [\%] & $142(130-153.5)$ & $127(121-141)$ \\
\hline UPAR [\%] & 117 (111.5-125) & 178.5 (164.5-189.5) \\
\hline
\end{tabular}

Results are shown as the percentage (\%) amount of detected $m R N A$ in each group of HaCat cell lines in comparison with $m R N A$ expression in the cell line stimulated with IgGs purified from healthy relatives of pemphigus patients (100\%)
A

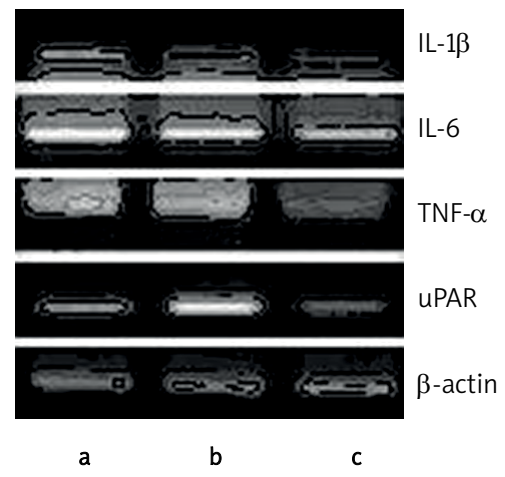

B

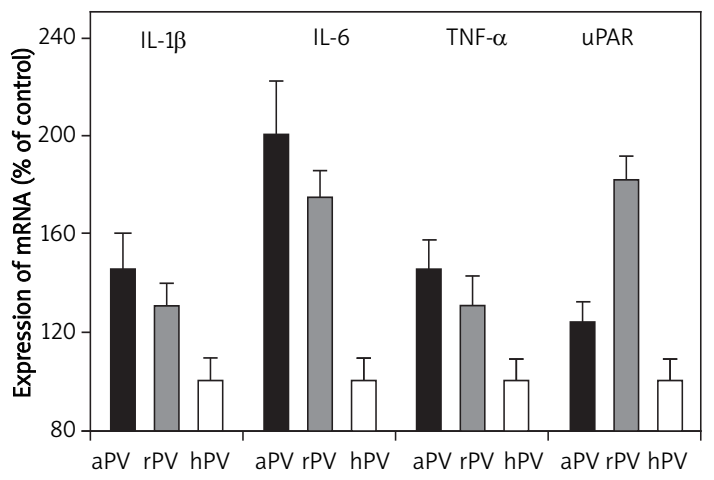

Figure 4. Effect of anti-Dsg-3 autoantibodies on expression of cytokines and UPAR in keratinocytes. Total RNA was extracted from the keratinocytes stimulated with anti-Dsg-3 autoantibodies isolated from PV patients at the active stage (lane $a$ ), in remission (lane b) and healthy relatives (lane $c$ ), analysed by RT PCR using relevant primers. In panel A mRNAs of IL-1 $\beta$, IL-6, TNF- $\alpha$, uPAR, and $\beta$-actin in HaCaT separated by electrophoresis in polyacrylamide gels are shown. Bands were visualized by UV light, recorded photographically and analysed densitometrically using Mul-

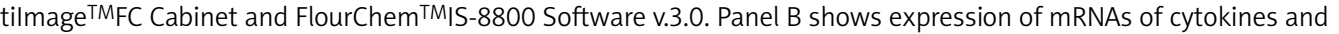
UPAR normalized to the $\beta$-actin mRNA intensity 
circulating antibodies in low titres in patients in whom there are no clinical lesions for a long time. Such a situation causes a therapeutic problem and prevents dermatologists from stopping treatment. Based on these observations we aimed to assess immunobiological properties of antibodies detected in patients in clinical remission in regard to their ability to induce loss of cell-cell contact, enhance mRNA expression of proteins involved in pemphigus pathogenesis and to trigger apoptosis.

The studies on the pathomechanism of acantholysis are still being performed but the whole process is not fully known. In multiple experimental studies it has been proven that PV-lgG causes many biochemical phenomena including transient, rapid increase in $\mathrm{Ca}^{2+}$, marked activation of phospholipase $C$ and transient increase in inositol 1,4,5triphosphate $\left(\mathrm{IP}_{3}\right)$ in cultured human keratinocytes [19]. The studies on the protein kinase $C$ revealed an increase in its activity after PV-lgG exposure and determined its important role in mediating the intracellular signalling events leading to loss of cellcell adhesion induced by PV-IgG binding to Dsg-3 $[20,21]$. Many experiments have aimed to explain the role of plasminogen activator in acantholysis. The obtained results are controversial and still need revision [22-26]. An increase in mRNAs for urokinase plasminogen activator (UPA) and for plasmin in cultured keratinocytes treated with PV-IgG was found [27], and an increase in tissue plasminogen activator mRNA in the perilesional skin from pemphigus patients was noted [28]. Based on these results, one may speculate about a role of activation of UPA in proteolysis of cell-cell attachment in pemphigus. Schuh et al. [29] tested inhibitors of the plasminogen activator system (anti-uPA, antitPA, anti-plasmin) with regard to their potential protective role. The authors found that these inhibitors failed to prevent PV-lgG mediated acantholysis, but acantholysis was effectively inhibited by the synthetic active site serine protease inhibitor. On the other hand, Xue et al. [30] suggest that monoclonal anti-uPAR antibodies have a protective role against acantholysis development. By immunohistochemical studies on the expression of plakoglobin and UPAR, strong expression of UPAR was found around acantholytic cells, probably resulting from dissociation of plakoglobin and Dsg3 mediated by PV-lgG binding [31]. Feliciani et al. [32] showed that pemphigus antibodies enhanced mRNA expression for UPA, IL-1 $\beta$ and TNF- $\alpha$ in vitro. They also concluded that IL-1 $\beta$ and TNF- $\alpha$ increased expression causes in the next step induction of urokinase plasminogen activator. Levels of several cytokines (IL-1 $\beta$, IL-6, TNF- $\alpha$ ) and inflammatory mediators including prostaglandins $\left(\mathrm{PGE}_{2}, \mathrm{PGF}_{1}, \mathrm{PGF}_{2}\right)$, thromboxane $B_{2}$ and leukotrienes $\left(L_{T B}, L_{4} C_{4}\right)$ were found to be increased in blister fluid and perile- sional skin in pemphigus patients $[33,34]$. It was also shown that TNF- $\alpha$ induces UPA in human endothelial cells treated with PV-lgG. Studies on the role of proinflammatory cytokines in pemphigus revealed that by using anti-IL- 1 and anti-TNF- $\alpha$ antibodies one may inhibit IgG-mediated acantholysis in vitro [35]. These studies and other reports indicate that IL-1 and TNF- $\alpha$ are overexpressed in PV and highlight their potential involvement in the pathogenesis of pemphigus. All the studies concerning expression of UPA and cytokines were performed with the use of PV-IgG obtained from patients at the active stage of the disease, while the role of antibodies found in patients in clinical remission or from healthy relatives has not been studied. Thus we attempted to analyse the influence of the latter on these phenomena. In our experiment we showed that anti-Dsg-3 antibodies isolated both from active and remission patients have the ability to bind at the surface of $\mathrm{HaCaT}$ cells and induce loss of cell-to-cell adhesion. After cell culture stimulation with these antibodies, increased expression of mRNAs for examined proinflammatory cytokines (IL-1 $\beta$, TNF- $\alpha$ and IL-6) was observed, which proves their role in pathogenesis of PV and is in line with observations of other authors [36, 37]. Although anti-Dsg- 3 antibodies purified from remission patients' sera did not cause statistically enhanced mRNA expression, they influenced this process, while IgGs from healthy relatives did not affect it at all. This observation proves the distinct properties of antibodies giving a "pemphigus-like" pattern in IIF isolated from healthy relatives and explains their lack of ability to initiate acantholysis. In contrast, UPAR mRNA expression was statistically increased under $\mathrm{HaCaT}$ incubation with antiDsg-3 antibodies purified from sera of patients in clinical remission, which may suggest the role of UPAR in maintaining the pathological process in later phases of the disease. Also in this case IgGs from healthy relatives caused no changes.

Abnormal activation of apoptosis and disturbances in apoptotic cell clearance may result in decreasing immunological tolerance and, as a consequence, the production of autoantibodies and the development of autoimmune diseases [38]. Currently, based on performed studies, apoptosis is accepted as one of the factors involved in acantholysis development [39, 40].

Caspases are key mediators in induction of apoptosis in different cells, among which caspase- 3 is known to play one of major roles in the process [41]. Keratinocyte apoptosis level may be established as the ratio of pro-apoptotic (Bax) and anti-apoptotic (Bcl-2) proteins from the $\mathrm{Bcl}-2$ family. It was demonstrated that $\mathrm{Bcl}-2$ can protect $\mathrm{HaCaT}$ cells against apoptosis [42] while apoptotic inducers enhance Bax protein expression [43]. 
In our study the decreased level of procaspase-3 (inactive form of caspase-3), which may be considered as a marker of increased apoptosis, with simultaneously a high level of Bax and a low level of $\mathrm{Bcl}-2$, suggests that purified anti-Dsg-3 antibodies obtained from active and remission PV patients are sufficient to cause a pro-apoptotic effect. Similar observations were obtained by Pelacho et al. [44], who showed in $\mathrm{HaCaT}$ cells that IgGs purified from patients with the mucocutaneous form of PV caused an apoptotic effect. These results suggest that anti-Dsg-3 antibodies may contribute to PV pathogenesis by enhancement of apoptosis. The IgGs isolated from healthy relatives of PV patients and from controls showed no pro-apoptotic effect, which testifies to their different immunobiological properties when compared to pemphigus autoantibodies circulating in the patients.

There are some controversial data revealing the presence of pemphigus antibodies in healthy relatives. However, in the majority of experiments these antibodies had no ability to bind in vivo with keratinocytes' superficial antigens and this observation raised the question of their significance. It was also raised whether the subjects with these antibodies are at increased risk for pemphigus development and whether they should be followed up. Our results seem to partially answer these questions and suggest that antibodies detected by IIF in healthy relatives are in fact "false" pemphigus antibodies, and the observed "fishnet-like" pattern might result from their binding to keratinocyte superficial antigens other than desmogleins, but this observation still requires further investigations.

The results obtained also give objective reasons for the necessity of long-term maintenance treatment of PV patients when any circulating antibodies are detected despite the lack of clinical manifestation.

\section{Acknowledgments}

This study was funded by the Polish Committee of Science and the Medical University of Lodz projects 2P05B07727 and 503-1152-1. We kindly thank Dr. Jaroslaw Bogaczewicz for his help in statistical analysis.

\section{References}

1. Udey MC, Stanley JR. Pemphigus - diseases of antidesmosomal autoimmunity. JAMA 1999; 282: 572-6.

2. Nguyen VT, Ndoye A, Grando SA. Novel human alpha9 acetylocholine2 receptor regulating keratinocyte adhesion is targeted by pemphigus vulgaris autoimmunity. Am J Pathol 2000; 157: 1377-91.

3. Nguyen VT, Ndoye A, Shultz LD, Pittelkow MR, Grando SA. Antibodies against keratinocyte antigens other than desmogleins 1 and 3 can induce pemphigus vulgaris-like lesons. J Clin Invest 2000; 106: 1467-79.
4. Raj D, Brash DE, Grossman D. Keratinocyte apoptosis in epidermal development and disease. J Invest Dermatol 2006; 126: 243-57.

5. Zhou P, Qian L, Kozopas KM, Craig RW. Mcl-1, a Bcl-2 family member delays of death of hematopoietic cells under variety of apoptosis-inducing conditions. Blood 1997; 89: 630-43.

6. Zhivotovsky B, Samali A, Gahm A, Orrenius S. Caspases: their intracellular localization and translocation during apoptosis. Cell Death Differ 1999; 6: 644-51.

7. Norbury CJ, Zhivotovsky B. DNA damage-induced apoptosis. Oncogene 2004; 23: 2797-808.

8. Puviani M, Marconi A, Cozzani E, Pincelli C. Fas ligand in pemphigus sera induces keratinocyte apoptosis through activation of caspase-8. J Invest Dermatol 2003; 120: 164-7.

9. Frusic-Zlotkin M, Pergamentz R, Michel B, et al. The interaction of pemphigus autoimmunoglobulins with epidermal cells: activation of the fas apoptotic pathway and the use of caspase activity for patogenecity tests of pemphigus patients. Ann N Y Acad Sci 2005; 1050: 371-9.

10. Wang X, Bregegere F, Frusic-Zlotkin M, Feinmesser M, Michel B, Milner Y. Possible apoptotic mechanism in epidermal cell acantholysis induced by pemphigus vulgaris autoimmunoglobulins. Apoptosis 2004; 9: 131-43.

11. Wolf R, Matz H, Rucco E, Rucco V. The putative role of apoptosis in the induction of pemphigus. Med Hypoteses 2005; 64: 44-5.

12. Brandsen R, Frusic-Zlotkin M, Lyubimov H, et al. Circulating pemphigus IgG in families of patients with pemphigus: comparison of indirect immunofluorescence, direct immunofluorescence, and immunoblotting. J Am Acad Dermatol 1997; 36: 44-52.

13. Kricheli D, David M, Frusic-Zlotkin M, et al. The distribution of pemphigus vulgaris-lgG subclasses and their reactivity with desmoglein 3 and 1 in pemphigus patients and their first-degree relatives. Br J Dermatol 2000; 143: 337-42.

14. Torzecka JD, Woźniak K, Kowalewski C, et al. Circulating pemphigus autoantibodies in healthy relatives of pemphigus patients: coincidental phenomenon with a risk of disease development? Arch Dermatol Res 2007; 299: 239-43.

15. Beutner EH, Jordon RE. Demonstration of skin antibodies in sera of pemphigus vulgaris patients by indirect immunofluorescence staining. Proc Soc Exp Biol Med 1964; 117: 505-10.

16. Cierniewska-Cieslak A, Cierniewski CS, Bledzka K, et al. Identification and characterization of two cation binding sites in the integrin beta3 subunit. J Biol Chem 2002; 277: 11126-34.

17. Smolarczyk K, Gils A, Boncela J, Declerck P, Cierniewski CS. Function-stabilizing mechanism of plasminogen activator inhibitor type 1 induced upon binding to alpha1-acid glycoprotein. Biochemistry 2005; 44: 12384-90.

18. Boukamp P, Petrussevska RT, Breitkreutz D, Hornung J, Markham A, Fusenisng NE. Normal keratinization in a spontaneously immortalized aneuploid human keratinocyte line. J Cell Biol 1988; 106: 761-71.

19. Esaki C, Seishima M, Yamada T, Osada K, Kitajima Y. Pharmacologic evidence for involvement of phospholipase C in pemphigus-lgG inositol 1,4,5-triphosphate generation, intracellular calcium increase, and plasminogen activator secretion in DJM-1 cells, a squamous cell carcinoma line. J Invest Dermatol 1995; 105: 329-33.

20. Kitajima Y, Aoyama Y, Seishima M. Transmembrane signaling for adhesive regulation of desmosomes and 
hemidesmosomes, and for cell-cell detachment induced by pemphigus IgG in cultured keratinocytes; involvement of protein kinase C. J Invest Dermatol Symp Proceedings 1999; 4: 137-44.

21. Osada K, Seishima M, Kitajima Y. Pemphigus IgG activates and translocates protein kinase $\mathrm{C}$ from the cytosol to the particulate/cytoskeleton fractions in human keratinocytes. J Invest Dermatol 1997; 108: 482-7.

22. Asano S, Seishima M, Kitajima Y. Phosphatidylinositolspecific-phospholipase $C$ cleaves urokinase plasminogen activator receptor from the cell surface and leads to inhibition of pemphigus-lgG-induced acantholysis in DJM-1 cells, a squamous cell carcinoma line. Clin Exp Dermatol 2001; 26: 289-95.

23. Hashimoto K, Wun TC, Baird J, Lazarus GS, Jensen PJ. Characterization of keratinocyte plasminogen activator inhibitors and demonstration of the prevention of pemphigus IgG-induced acantholysis by a purified plasminogen activator inhibitor. J Invest Dermatol 1989; 93: 310-4.

24. Lo Muzio L, Pannone G, Staibano S, et al. Strict correlation between UPAR and plakoglobin expression in pemphigus vulgaris. J Cutan Pathol 2002; 29: 540-8.

25. Mahoney MG, Wang ZH, Stanley JR. Pemphigus vulgaris and pemphigus foliaceus antibodies are pathogenic in plasminogen activator knockout mice. J Invest Dermatol 1999; 113: 22-5.

26. Yamamoto Y, Aoyama Y, Shu E, Tsunoda K, Amagai M, Kitajima $Y$. No activation of urokinase plasminogen activator by anti-desmoglein 3 monoclonal IgG antibodies in cultured human keratinocytes. J Dermatol Sci 2007; 47: 119-25.

27. Seishima M, Satoh S, Nojiri M, Osada K, Kitajima Y. Pemphigus IgG induces expression of urokinase plasminogen activator receptor on the cell surface of cultured keratinocytes. J Invest Dermatol 1997; 109: 650-5.

28. Baird J, Lazarus GS, Belin D, et al. mRNA for tissue-type plasminogen activator is present in lesional epidermis from patients with psoriasis, pemphigus, or bullous pemphigoid, but is not detected in normal epidermis. J Invest Dermatol 1990; 95: 548-52.

29. Schuh T, Besch R, Braungart E, et al. Protease inhibitors prevent plasminogen-mediated, but not pemphigus vulgaris-induced, acantholysis in human epidermis. Biol Chem 2003; 384: 311-5.

30. Xue W, Hashimoto K, Toi Y. Functional involvement of urokinase-type plasminogen activator receptor in pemphigus acantholysis. J Cutan Pathol 1998; 25: 469-74.

31. Andl C, Stanley JR. Central role of the plakoglobin-binding domain for desmoglein 3 incorporation into desmosomes. J Invest Dermatol 2001; 117: 1068-74.

32. Feliciani C, Toto P, Wang B, Sauder DR, Amerio P, Tulli A. Urokinase plasminogen activator mRNA is induced by IL-1 alpha and TNF-alpha in in vitro acantholysis. Exp Dermatol 2003; 12: 466-71.

33. D'Auria L, Bonifati C, Mussi A, et al. Cytokines in the sera of patients with pemphigus vulgaris: interleukin- 6 and tumor necrosis factor-alpha levels are significantly increased as compared to healthy subjects and correlate with disease activity. Eur Cytokine Netw 1997; 8: 383-7.

34. Grando SA, Glukhenky BT, Drannik GN, Epshtein EV, Kostromin AP, Korostash TA. Mediators of inflammation in blister fluids from patients with pemphigus vulgaris and bullous pemphigoid. Arch Dermatol 1989; 125: 925-30.
35. Feliciani C, Toto P, Amerio P, et al. In vitro and in vivo expression of interleukin-1alpha and tumor necrosis factor-alpha mRNA in pemphigus vulgaris: interleukin-1 alpha and tumor necrosis factor-alpha are involved in acantholysis. J Invest Dermatol 2000; 114: 71-7.

36. Alecu M, Alecu S, Coman G, Gălățescu E, Ursaciuc C. ICAM-1, ELAM-1, TNF-alpha and IL-6 in serum and blister liquid of pemphigus vulgaris patients. Roum Arch Microbiol Immunol 1999; 58: 121-31.

37. Keskin DB, Stern JN, Fridkis-Hareli M, Razzaque Ahmed A. Cytokine profiles in pemphigus vulgaris patients treated with intravenous immunoglobulins as compared to conventional immunosuppressive therapy. Cytokine 2008; 41: 315-21.

38. Giovannetti A, Pierdominici M, Di lorio A, et al. Apoptosis in the homeostasis of the immune system and in human immune mediated diseases. Curr Pharm Des 2008; 14: 253-68.

39. Frusić-Zlotkin M, Raichenberg D, Wang X, David M, Michel B, Milner Y. Apoptotic mechanism in pemphigus autoimmunoglobulins-induced acantholysis: possible involvement of the EGF receptor. Autoimmunity 2006; 39: 563-75.

40. Gniadecki R, Jemec GB, Thomsen BM, Hansen M. Relationship between keratinocyte adhesion and death: anoikis in acantholytic diseases. Arch Dermatol Res 1998; 290: 528-32.

41. Slee EA, Adrian C, Martin SJ. Serial killers: ordering caspase activation events in apoptosis. Cell Death Differ 1999; 6: 1067-74.

42. Tiberio R, Marconi A, Fila C, et al. Keratinocytes enriched for stem cells are protected from anoikis via an integrin signaling pathway in a $\mathrm{Bcl}-2$ dependent manner. FEBS Lett 2002; 524: 139-44.

43. Seyedhassani SM, Houshmand M, Kalantar SM, et al. BAX pro-apoptotic gene alterations in repeated pregnancy loss. Arch Med Sci 2011; 7: 117-22.

44. Pelacho B, Natal C, Espana A, Scanchez-Carpintero I, Iraburu MJ, Lopez-Zabalza MJ. Pemphigus vulgaris autoantibodies induce apoptosis in HaCaT keratinocytes. FEBS Lett 2004; 256: 6-10. 